\title{
Study on Prediction Method for Postconstruction Settlement of Loess Fill Foundation in Northern Shaanxi, China
}

\author{
Kui Liu $\mathbb{D}^{1,2}$ Kangze Yuan $\left.{ }^{1}\right)^{1}$ and Boyi Shi $\mathbb{D}^{1}$ \\ ${ }^{1}$ Department of Geological Engineering, College of Geological Engineering and Surveying and Mapping, Chang'an University, \\ No. 126 Yanta Road, Xi'an 710054, Shaanxi, China \\ ${ }^{2}$ China Information Industry Engineering Investigation and Research Institute, Xi'an 710001, China \\ Correspondence should be addressed to Kangze Yuan; yuan135830@126.com
}

Received 18 February 2020; Revised 4 November 2020; Accepted 2 December 2020; Published 15 December 2020

Academic Editor: Xiaodong Hu

Copyright (c) 2020 Kui Liu et al. This is an open access article distributed under the Creative Commons Attribution License, which permits unrestricted use, distribution, and reproduction in any medium, provided the original work is properly cited.

\begin{abstract}
In order to solve the problem of shortage of construction land in the loess hilly and gully area of northern Shaanxi, the local people usually adopted the method of excavating and filling. The postconstruction settlement was an important index to evaluate the stability of the loess fill foundation. Through laboratory test analysis, the stress-strain and the strain-time relationship of compacted loess were obtained. It showed that the stress-strain curves varied as power functions, and the relationship between strain and time was hyperbolic. Based on the layerwise summation method, a creep equation to predict the postconstruction settlement of loess fill foundation was established. The field monitoring data show that the fitting effect is better. Using this equation, the postconstruction settlement of loess fill foundation with different compaction coefficients and thickness was predicted. Finally, the stability evaluation criteria of loess fill foundation with various thickness and compaction coefficient were proposed. This method provided a new idea to solve the problem of postconstruction settlement of loess fill foundation.
\end{abstract}

\section{Introduction}

Loess is widely distributed throughout the world, including Asia, southern Europe and Africa, central and northern Russia, northern France, and American Midwest [1-4]. Among these areas, China is the country with the largest loess area in the world. The loess area is about $6.4 \times 10^{5} \mathrm{~km}^{2}$, accounting for about $10 \%$ of the total area of the world loess $[5,6]$. The Loess Plateau is the most representative area because the loess is stratigraphically complete, continuously distributed, and has the greatest thickness [7]. With the development of the local economy and the increase of related engineering activities, the frequency of occurrence of geological disasters in the region has increased rapidly. Common geological disasters include loess caves, ground fissures, ground settlement, geological dilapidation, and loess landslides, among which the ground settlement is the most common and destructive [8-11]. The loess hilly and gully region of Yan'an City in northern Shaanxi is restricted by special topographic and geomorphological conditions, and towns are distributed along gully slopes [12]. It is very prominent for the contradiction between urban development and the shortage of construction land. In order to solve the problem, most local people use the method of digging high and filling low to construct land artificially. There are a large number of fill foundations in the major gullies of Yan'an City. The special physical and mechanical properties of loess fill determine its poor engineering performance. In particular, in 2013, Yan'an City suffered from the longest and strongest continuous heavy rainfall since the meteorological records in 1945. It is a oncein-a-century event. The monthly accumulated rainfall was $581 \mathrm{~mm}$, and the maximum daily rainfall was $143.7 \mathrm{~mm}$ $[13,14]$, which resulted in a large number of disasters for fill foundation buildings in the urban ditches of Yan'an City. The main reason is that the uneven settlement of the loess fill foundation causes the cracking and deformation of the superstructure. Therefore, it is necessary to carry out the prediction research on the settlement of loess fill 
foundation, to provide the basis for the quality control of loess fill and the treatment of building disasters.

The current research on loess fill foundation mainly focuses on the detection of foundation stability. Yang et al., 2013, found that the construction process, construction method, and the influence of the filled soil type on the roadbed settlement, to adjust the construction method and subside regularity can be summarized [15]. Mei et al., 2012, studied that the deep collapsible loess foundation can be effectively reinforced by dynamic compaction, that the stability of foundation is good, and that the loess collapse in the reinforced range is eliminated basically [16]. Postconstruction settlement of fill foundation is mainly composed of two parts: one is a minimal amount of consolidation settlement and the other is creep settlement. After consolidation settlement is completed, the volume of soil decreases under the long-term action of constant load and the creep settlement develops very slowly and lasts for a long time. It is the main component of postconstruction settlement and has a great impact on buildings. At present, there are mainly the following aspects for the calculation of foundation deformation: one is the layered summation method specified in Basic Design Criterion of Architecture Base [17], which is used to calculate the settlement in the compressed layer caused by the additional stress of the foundation. The calculation model used in this method is quite different from the actual one. At the same time, it is difficult to obtain the actual geotechnical parameters, which makes the calculation error of this method larger. Many scholars have put forward many improved methods on this basis. Jiao et al., 1982, proposed the string modulus method based on the P-S curve of the in situ test [18]. Chun et al., 2018, considered the modified Cam-Clay and Mohr-Coulomb models, and the compressive modulus was derived by considering the plastic deformations under the condition of $\mathrm{K}_{0}[19]$.

The other is the numerical calculation method, including the finite element method and the finite difference method. Yang et al., 2012, used the transfer matrix method to calculate and analyze the settlement law of foundation and found that increasing the width of foundation and deformation modulus of foundation can improve the antioverturning performance of foundation while decreasing the width of foundation and increasing the deformation modulus of foundation can reduce the settlement of the foundation [20]. The theory of this method is relatively perfect because various states, such as elastic-plastic, can be considered. However, it is still challenging to obtain the soil constitutive model. Its calculation parameters are also derived from the laboratory test, which is quite different from the actual data. At the same time, due to the extensive implementation of engineering monitoring and the accumulation of monitoring data, people also began to predict the foundation settlement based on the measured data $[13,21,22]$. The main methods are curve fitting, grey theory, artificial neural network, and genetic algorithm, which are pure mathematical methods and have high requirements on the measured data [23].
Aiming at the shortcomings of the traditional methods, a new method for calculating postconstruction settlement of loess fill foundation is proposed in this paper. According to the characteristics of the loess fill foundation, the remoulded loess samples which are similar to the water content and dry density of field fill are studied in the laboratory. Through indoor compaction test and high-pressure consolidation test, the postconstruction settlement of loess fill foundation is calculated by using the principle of the comprehensive layered method. This method overcomes the influence of the traditional sampling disturbance, and the calculation effect is better through the field monitoring data verification.

\section{Material and Methods}

2.1. Properties of Loess. The tested material is loess taken from the filling material of a community in Yan'an City, China. Figure 1 shows the major distribution map of the Loess Plateau in China and the sampling location. Meanwhile, the tested material is mainly a mixture of $\mathrm{Q}_{3}$ and $\mathrm{Q}_{2}$ loess. Among them, the $\mathrm{Q}_{3}$ loess of the late Pleistocene is the product of 100,000 to 5,000 years ago and is called Malan loess. The $\mathrm{Q}_{2}$ loess of the Middle Pleistocene is the product of about 700,000 to 100,000 years ago and is called Lishi loess. Meanwhile, the paleosoil and calcareous nodule in $\mathrm{Q}_{2}$ loess are removed. The particle size composition of the loess is tested by Bettersize 2000 laser particle size distributor (measurement range of $0.02-2000 \mu \mathrm{m}$ and a relative error of $<1 \%$ ), in which the clay content accounts for about $10 \%$, the silt content accounts for about $77 \%$, and the sand content accounts for about $13 \%$. Some basic geotechnical properties are summarized in Table 1.

The loess was air-dried, pulverized by a wooden mallet, and then its mineral component was tested by using the X-ray diffraction method (Bruker D8 Advance using graphite monochromatic copper radiation $(\mathrm{Cu} \mathrm{Ka})$ at $40 \mathrm{kV}$, $30 \mathrm{~mA}$ over the $2 \theta$ range $10^{\circ}-80^{\circ}$ ), as shown in Table 2 . The primary minerals of the loess are mainly quartz, feldspar, and calcite, and the clay mineral is illite.

The compaction test was conducted according to the Unified Soil Classification System (USCS; ASTM 2011) [24]. The compacting curve (Figure 2) shows that the optimum water content of the tested soil is $14.0 \%$, and the corresponding maximum dry density is $1.86 \mathrm{~g} / \mathrm{cm}^{3}$.

\subsection{Prediction Method Establishment. The establishment of} this method is to fit the strain-time relationship of compacted loess with different moisture content and dry density under different pressures. It is found that the time/strain and time of Yan'an City compacted loess under different pressures are linearly correlated. After transformation, it can be concluded that the relationship between strain and time is hyperbolic. Combined with the study on compacted loess under confined conditions by Chen et al., 2010 [25], it is found that the relationship between vertical compressive stress and vertical compressive strain conforms to the form of a power function. The empirical creep equation of the compact loess can be obtained. Therefore, the settlement of 


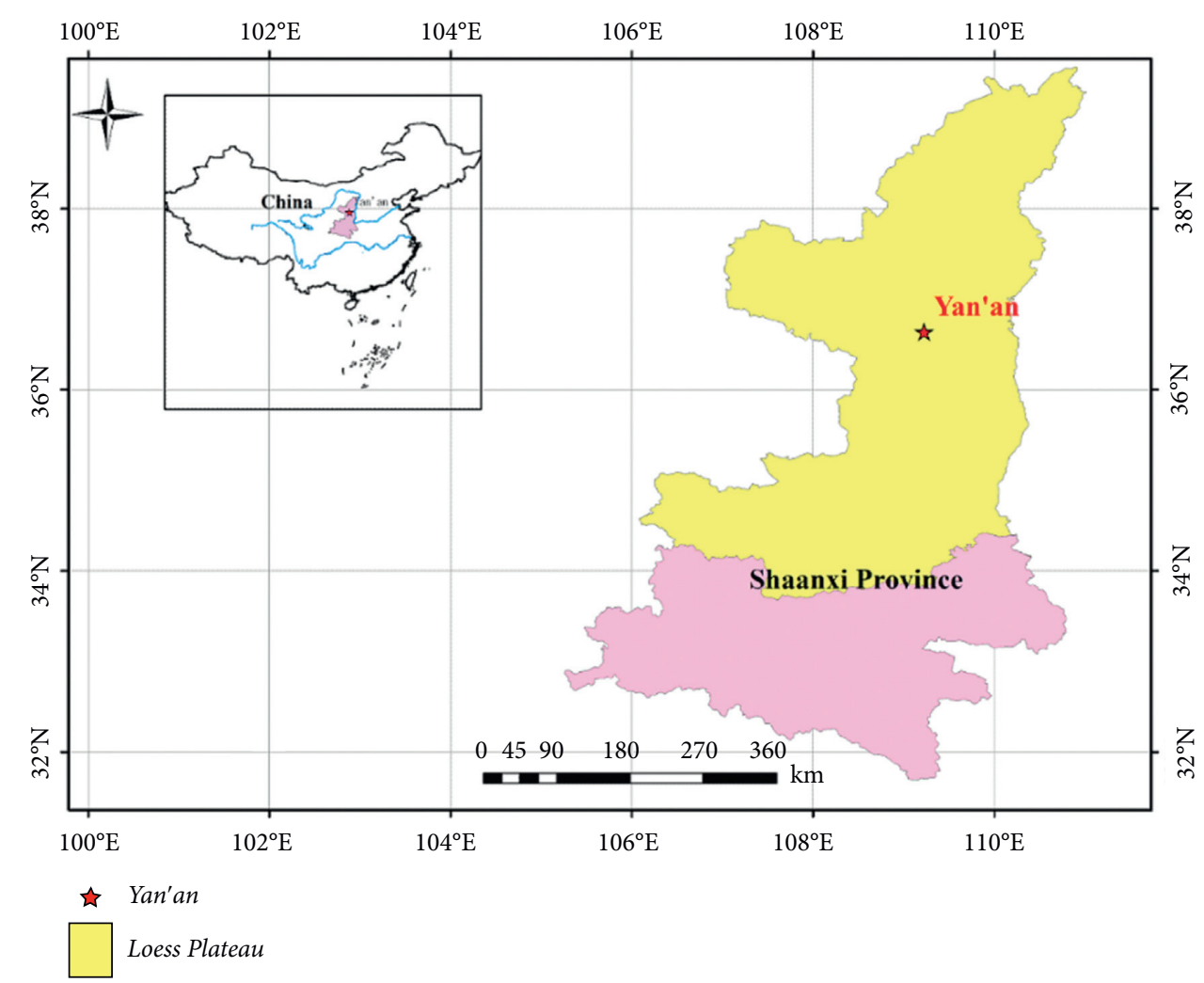

Figure 1: Major occurrence of Loess Plateau in Shaanxi and sampling location at the excavation site.

TABle 1: Some basic geotechnical properties of the tested material.

\begin{tabular}{lcccccc}
\hline Sample & $\begin{array}{c}\text { In situ density } \\
\left(\mathrm{g} / \mathrm{cm}^{3}\right)\end{array}$ & $\begin{array}{c}\text { Natural moisture } \\
\text { content }(\%)\end{array}$ & Specific gravity & Plastic limit $\left(\omega_{P} / \%\right)$ & Liquid limit $\left(\omega_{L} / \%\right)$ & Plasticity index $\left(I_{p}\right)$ \\
\hline Value & 1.65 & 14.21 & 2.72 & 17.1 & 25.6 & 8.5 \\
\hline
\end{tabular}

TABle 2: Mineral component of the tested material.

\begin{tabular}{lc}
\hline Mineral component & Percentage \\
\hline Quartz & 50.2 \\
Feldspar & 13.1 \\
Calcite & 11.4 \\
Dolomite & 5.3 \\
Illite & 14.5 \\
Chlorite & 5.5 \\
\hline
\end{tabular}

the loess fill with thickness $H$ under the load $p$ is predicted, and the postconstruction settlement of the fill foundation is obtained.

\section{Results and Discussion}

3.1. Stress-Strain Relationship of Compacted Loess. The consolidation test of lateral limit drainage is carried out by making compacted loess samples with different dry density and water content. According to the optimal water content, four categories of water content are set, which are $6 \%, 10 \%$, $14 \%$, and $18 \%$, respectively. According to the maximum dry density of the field filling foundation loess, five

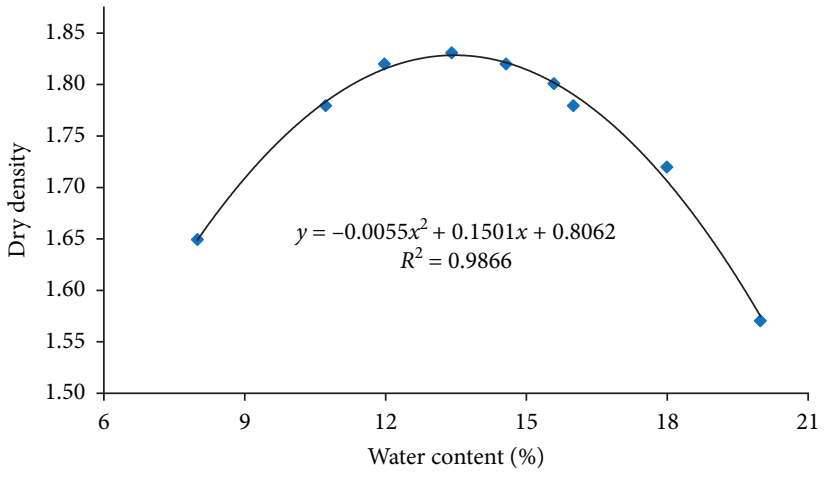

Figure 2: Compaction curve of loess samples.

categories of dry density are set, which are $1.55 \mathrm{~g} / \mathrm{cm}^{3}$, $1.60 \mathrm{~g} / \mathrm{cm}^{3}, 1.65 \mathrm{~g} / \mathrm{cm}^{3}, 1.70 \mathrm{~g} / \mathrm{cm}^{3}$, and $1.75 \mathrm{~g} / \mathrm{cm}^{3}$, respectively (corresponding compaction coefficients are 0.83 , $0.86,0.89,0.91$, and 0.94). The lateral limit drainage consolidation tests for samples with different water content and dry density are carried out by high-pressure consolidation, and the pressure setting is shown in Figure 3. The pressure loading time of each stage is $6 \mathrm{~s}, 15 \mathrm{~s}, 1 \mathrm{~min}$, 


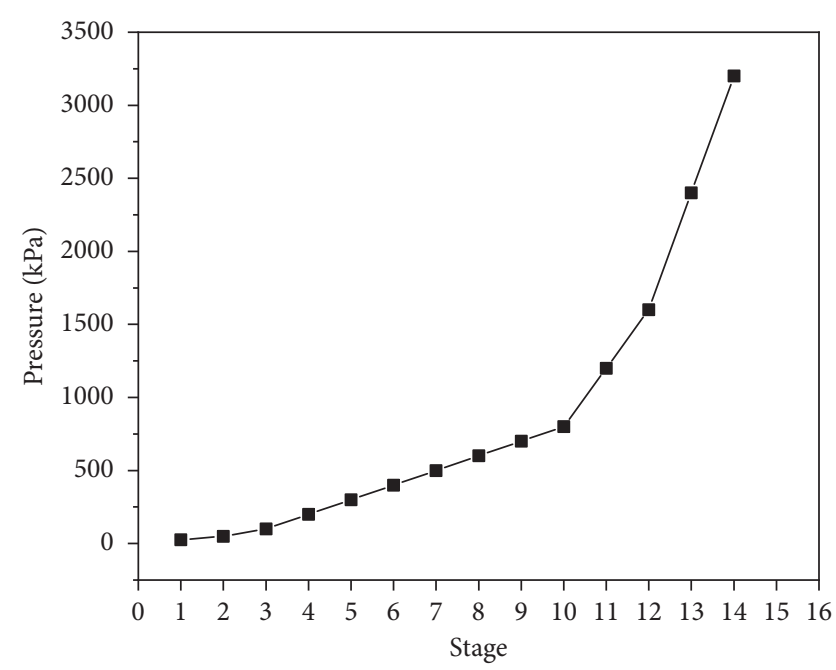

FIgURE 3: Pressure setting for high-pressure consolidation test.

$2.25 \mathrm{~min}, 4 \mathrm{~min}, 6.25 \mathrm{~min}, 9 \mathrm{~min}, 12.25 \mathrm{~min}, 16 \mathrm{~min}$, $20.25 \mathrm{~min}, 25 \mathrm{~min}, 30.25 \mathrm{~min}, 36 \mathrm{~min}, 42.25 \mathrm{~min}, 49 \mathrm{~min}$, $64 \mathrm{~min}, 100 \mathrm{~min}, 200 \mathrm{~min}, 400 \mathrm{~min}, 23 \mathrm{~h}$, and $24 \mathrm{~h}$, and the dial indicator value is recorded.

At the beginning of loading, due to the insufficient contact or no contact between the loess sample and the instrument, the strain value under the first level load $(25 \mathrm{kPa})$ is much larger than the actual value. Therefore, in order to reduce the error, this paper takes $25 \mathrm{kPa}$ load as the preload when dealing with the high-pressure consolidation test results, which is not included in the strain analysis. The relationship curves of pressure and lateral limit strain with different dry density and water content are obtained, respectively, as shown in Figure 4, The curve of lateral limit strain changing with time under each level of load is obtained, and some test curves are shown in Figure 5.

It can be seen from Figure 4 that the variation of stressstrain curves of compacted loess can be divided into three stages depending on the increase of loading. In the first stage, when the pressure is between $0 \mathrm{kPa}$ and $400 \mathrm{kPa}$, the stressstrain curve of the compacted loess increases rapidly and linearly. In the second stage, when the pressure is between $400 \mathrm{kPa}$ and $1600 \mathrm{kPa}$, the growth rate of the stress-strain relation curve of the compacted loess decreases gradually. In the last stage, when the pressure exceeds $1600 \mathrm{kPa}$, the growth rate of the stress-strain relation curve basically remains unchanged. With the increase of water content, the vertical strain of compacted loess samples with the same density showed an upward trend. Under the same water content, the lateral strain of compacted loess gradually decreases with the increase of dry density. When the moisture content is $6 \%$, the stress-strain curves of the compacted loess with a dry density of $1.65 \mathrm{~g} / \mathrm{cm}^{3}, 1.70 \mathrm{~g} / \mathrm{cm}^{3}$, and $1.75 \mathrm{~g} / \mathrm{cm}^{3}$ are similar, and the dry density has little influence on the lateral strain.

Figure 5 shows the strain-time curve under different pressures at a moisture content of $6 \%$ and a dry density of $1.55 \mathrm{~g} / \mathrm{cm}^{3}$. The strain increases with the increase of pressure, and the strain-time curve under different pressures increases rapidly with the increase of time and then tends to stabilize. When the deformation does not increase in a certain period of time, it is considered to be stable. Since the strain-time curves corresponding to other water content and dry density at different pressures are basically consistent with the curve trend in Figure 5, they will not be shown here.

3.2. Empirical Creep Equation of Compacted Loess. Creep refers to the process that the deformation of material increases with time under the action of constant load, and it is the main part of the settlement of postconstruction fill foundation. In order to evaluate the stability of loess fill foundation, it is necessary to determine the settlement amount and postconstruction settlement rate. The straintime relationship and stress-strain relationship of the compacted loess under different pressures are analyzed, respectively, and the empirical creep equation of compacted loess is obtained by the fitting.

By analyzing and fitting the strain-time relationship of the test data, it is found that there is a linear correlation between $t / \varepsilon$ and $t$ of compacted loess under different pressures, as shown in Figure 6 (the test data in the figure shows that the water content is $14 \%$, the dry density is $1.65 \mathrm{~g} /$ $\mathrm{cm}^{3}$, and the load is $3200 \mathrm{kPa}$ ). The larger the load, the better the correlation, so there is

$$
\frac{t}{\varepsilon}=c t+d
$$

After the exchange, we get

$$
\varepsilon=\frac{t}{c t+d}
$$

That is to say, the relationship between strain and time of compacted loess can be described in hyperbolic form, where $c$ and $d$ are parameters, $t$ is the time of this process (h), and $\varepsilon$ is the strain of this process (\%).

In terms of the stress-strain relationship of soil, the stress-strain relationship of soil under the lateral limit was more hyperbolic [26]. Chen et al., 2010, believed that, under the lateral limit condition, the relationship between vertical compressive stress and vertical compressive strain conformed to the form of the power function [25]. Through the analysis and fitting of the stress-strain relationship of the test data, it is found that the stress-strain relationship of the compacted loess is more consistent with the form of the power function, as shown in Figure 7 the test data in the figure shows that the water content is $14 \%$, the dry density is $1.65 \mathrm{~g} / \mathrm{cm}^{3}$, and the load is $3200 \mathrm{kPa}$, namely,

$$
\varepsilon=k p^{n}
$$

where $k$ and $n$ are parameters, $p$ is the pressure of this process $(\mathrm{kPa})$, and $\varepsilon$ is the strain of this process (\%).

According to equation (3), the stress-strain relationship of compacted loess samples in the same state is fitted, and it is found that there is the following relationship between parameters $k, n$, and $t(t>0)$; namely, 


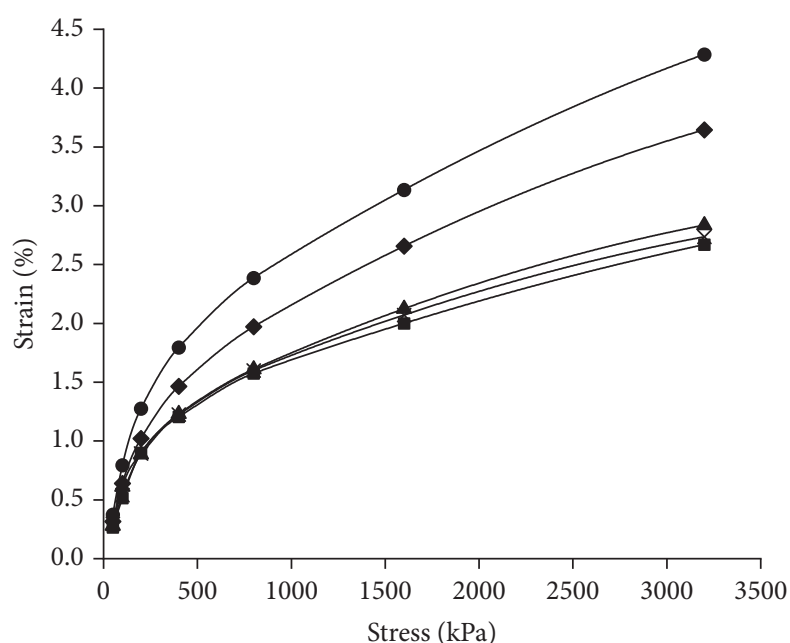

$$
\begin{array}{ll}
\longrightarrow \rho \mathrm{d}=1.55 \mathrm{~g} / \mathrm{cm}^{3} & \leftarrow \rho \mathrm{d}=1.70 \mathrm{~g} / \mathrm{cm}^{3} \\
\longrightarrow \rho \mathrm{d}=1.60 \mathrm{~g} / \mathrm{cm}^{3} & \longrightarrow \rho \mathrm{d}=1.75 \mathrm{~g} / \mathrm{cm}^{3} \\
\multimap \rho \mathrm{d}=1.65 \mathrm{~g} / \mathrm{cm}^{3} &
\end{array}
$$

(a)

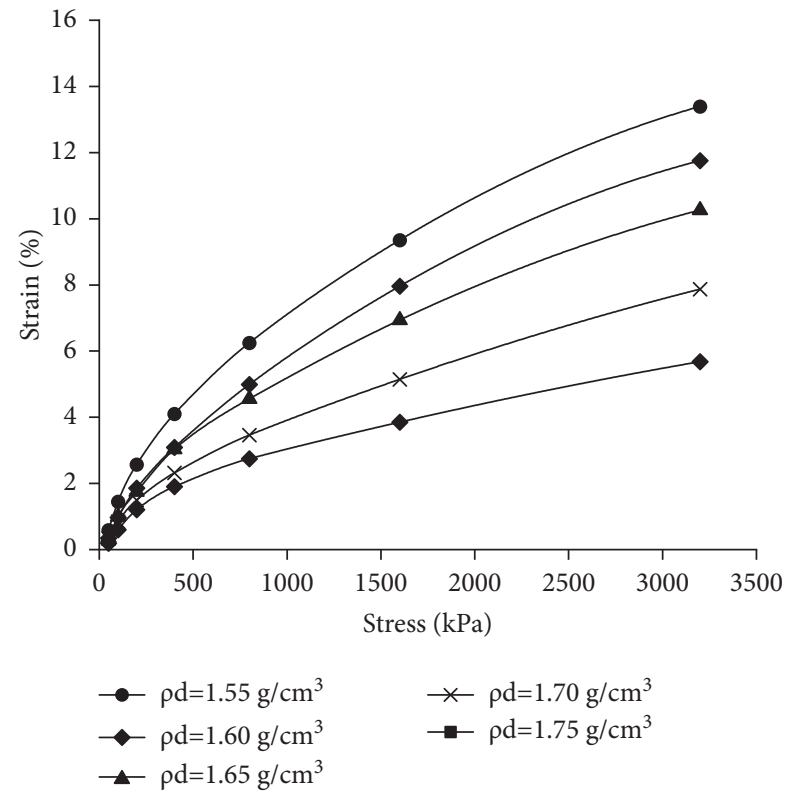

(c)

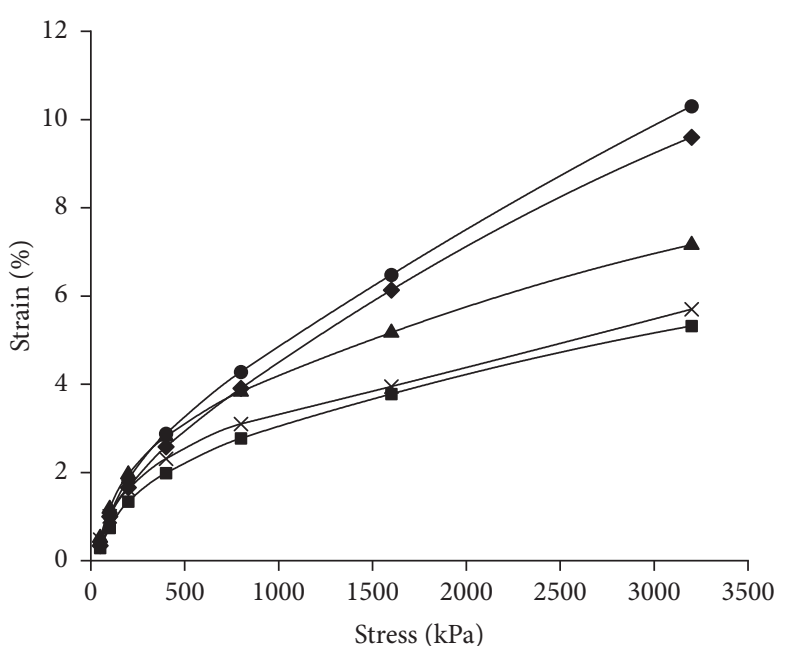

$$
\begin{array}{ll}
\longrightarrow \rho \mathrm{d}=1.55 \mathrm{~g} / \mathrm{cm}^{3} & \rightarrow \rho \mathrm{d}=1.70 \mathrm{~g} / \mathrm{cm}^{3} \\
\multimap \rho \mathrm{d}=1.60 \mathrm{~g} / \mathrm{cm}^{3} & \rightarrow \rho \mathrm{d}=1.75 \mathrm{~g} / \mathrm{cm}^{3} \\
\leftarrow \rho \mathrm{d}=1.65 \mathrm{~g} / \mathrm{cm}^{3} &
\end{array}
$$

(b)

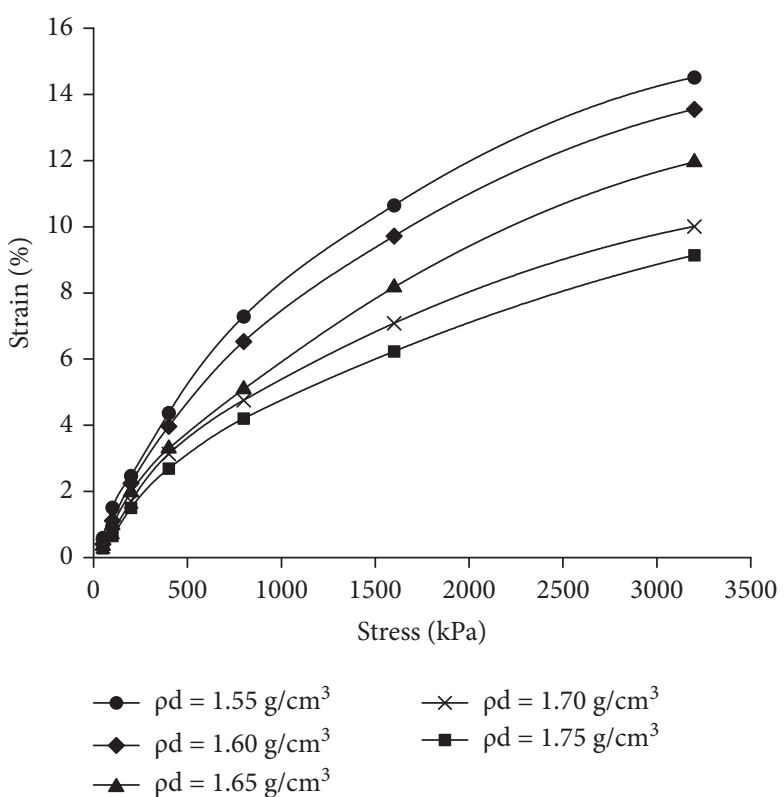

(d)

FIGURE 4: Stress-strain curves of compacted loess with different water content. (a) Water content is 6\%. (b) Water content is $10 \%$. (c) Water content is $14 \%$. (d) Water content is $18 \%$.

$$
\begin{aligned}
& k=\alpha t^{\beta}, \\
& n=\frac{t}{e t+f},
\end{aligned}
$$

where $\alpha, \beta, e$, and $f$ are parameters and $t$ is the time of this process (h).

Based on the above analysis, the relationship between stress and strain of the compacted loess is expressed by a power function, and the relationship between strain and time is expressed by a hyperbola. Combined with equations
(2)-(5), the empirical creep equation of the compact loess can be obtained as follows:

$$
\varepsilon=\alpha t^{\beta} p^{t /(e t+f)}
$$

where $\alpha, \beta, e$, and $f$ are parameters, $p$ is stress $(\mathrm{kPa}), t$ is the time of this process $(\mathrm{h})$, and $\varepsilon$ is the strain of this process (\%).

Equation (6) is used to derive the time:

$$
\frac{\partial \varepsilon}{\partial t}=\frac{\alpha}{t^{1-\beta}} p^{t /(e t+f)}\left(\beta+\frac{f t \ln p}{(e t+f)^{2}}\right) .
$$




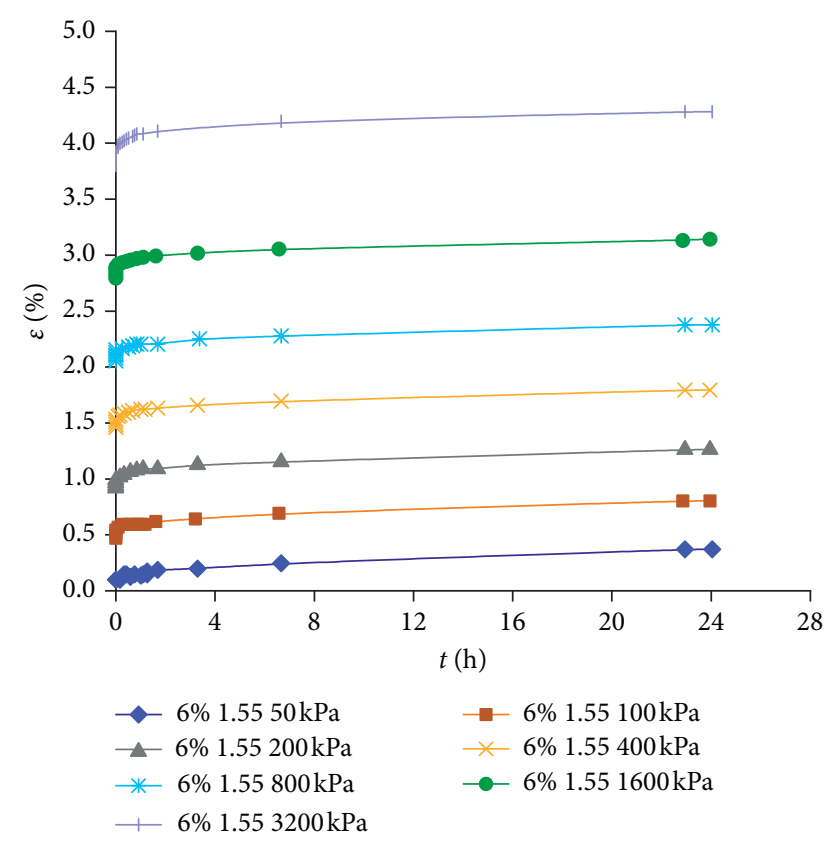

FIGURE 5: Stress-time curves of compacted loess with water content $6 \%$.

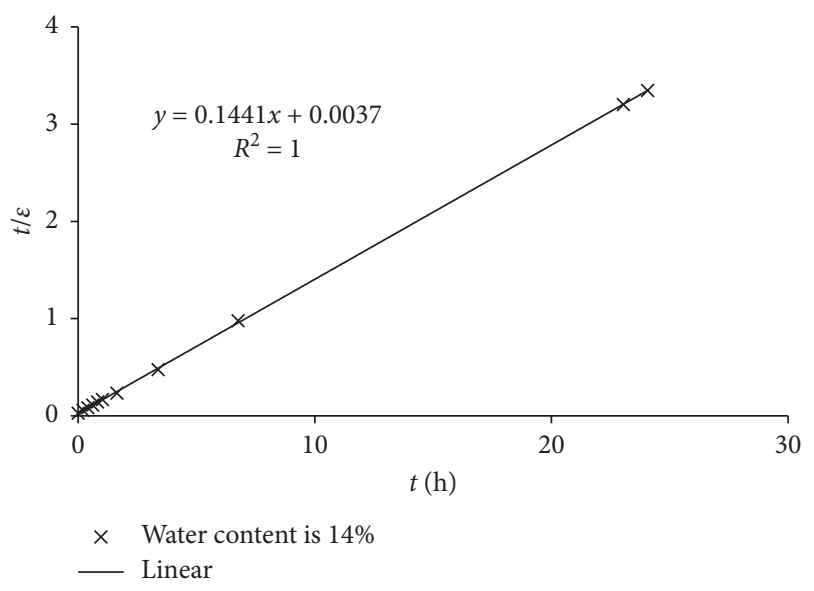

Figure 6: Curves between $t / \varepsilon$ and $t$.

According to the strain-time curve, $(\partial \varepsilon / \partial t)>0$. When $t \longrightarrow \infty, \partial \varepsilon / \partial t \mid t \longrightarrow \infty=0$, indicating that, as time goes on, the strain rate decreases and gradually approaches 0 ; that is, the strain value of loess tends to a certain value after a long action time.

For the settlement of homogeneous loess fill with thickness $H$ under the action of load $p$, considering the creep characteristics of compacted loess, the following equation can be used:

$$
S=\varepsilon H=\alpha t^{\beta} p^{t /(e t+f)} H,
$$

where $\alpha, \beta, e$, and $f$ are parameters, $p$ is stress $(\mathrm{kPa}), t$ is the time of this process (h), $\varepsilon$ is the strain of this process (\%), $H$ is the thickness of loess fill foundation $(\mathrm{m})$, and $S$ is the amount of foundation settlement $(\mathrm{cm})$.

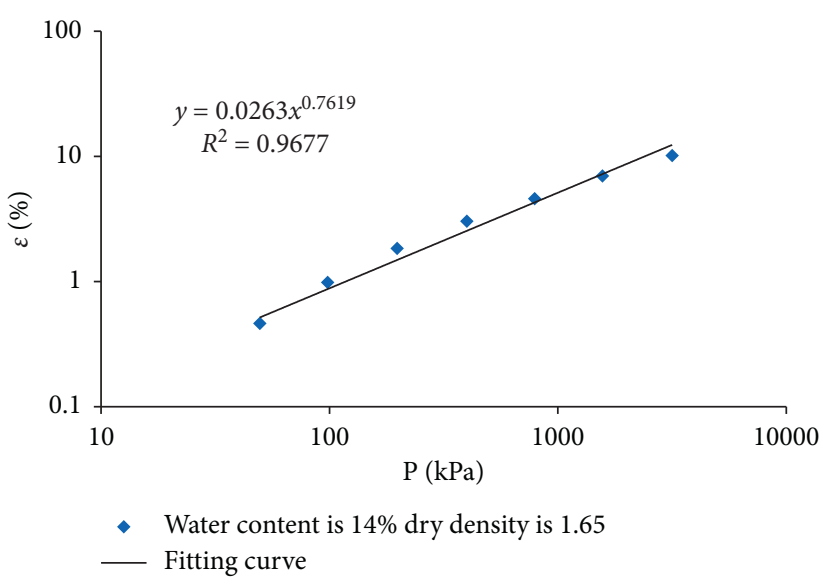

Figure 7: Curves between $\varepsilon$ and $p$.

According to the above equation and the layer-summation method, the settlement of loess foundation with thickness $H$ under the action of dead-weight can be calculated. The calculation equation of settlement is as follows:

$$
S=\int_{0}^{H} \varepsilon d z=\int_{0}^{H} \alpha t^{\beta} p^{t /(e t+f)} d z .
$$

Assuming that the filling foundation soil is even, a load of a certain soil layer in the fill foundation on the deadweight of the upper soil layer is

$$
p=r z
$$

where $r$ is the weight of loess $\left(\mathrm{kN} / \mathrm{m}^{3}\right)$ and $z$ is the depth of the test $(m)$.

Equation (9) can be expressed as

$$
S=\int_{0}^{r H} \frac{1}{r} \alpha t^{\beta} p^{t /(e t+f)} d p=\frac{\alpha t^{\beta}(e t+f)}{r((e+1) t+f)}(r H)^{(t /(e t+f))+1} .
$$

In this equation, the settlement of the foundation is only related to the time and the state of the loess. The state of the loess mainly includes two indexes: the water content and compaction coefficients. In the equation, the parameters $\alpha$, $\beta, e, f$, and $r$ of the loess are mainly reflected. The postconstruction settlement of the fill foundation can be obtained by determining the relevant parameters in the formula through the test.

3.3. Verification of Empirical Equations. Based on the monitoring data of field projects, the applicability of the above equation (11) is verified. The compaction coefficient of one loess fill foundation in Yan'an City is 0.87-0.93, and the dry density of loess samples corresponding to the laboratory test is $1.65-1.75 \mathrm{~g} / \mathrm{cm}^{3}$. Therefore, JC01 and JC02 monitoring data in the project are, respectively, used to verify the empirical equation. These two monitoring data points are located in Baota District, Yan'an City. According to the results of the high-pressure consolidation test, the parameters $\alpha, \beta, e, f$ and the corresponding soil gravity $r$ of the compacted loess sample are calculated, respectively. At this 
time, when the water content is $14 \%$, the dry density is $1.60 \mathrm{~g} / \mathrm{cm}^{3}, 1.65 \mathrm{~g} / \mathrm{cm}^{3}, 1.70 \mathrm{~g} / \mathrm{cm}^{3}$, and $1.75 \mathrm{~g} / \mathrm{cm}^{3}$, respectively; and when the water content is $18 \%$, the dry density is $1.65 \mathrm{~g} / \mathrm{cm}^{3}$. The calculation results are listed in Table 3. Next, the settlement monitoring data of each hole is compared with the empirical creep equation.

3.3.1. JCO1 Monitoring Point. According to the water content test data of JC01 monitoring point, the average water content of the hole is about $14 \%$, and the compactness is 0.93, so the empirical equation can be calculated by using the parameter with the water content of $14 \%$ and dry density of $1.73 \mathrm{~g} / \mathrm{cm}^{3}$ (the parameters in Table 1 are obtained by interpolation), and the calculation results are compared with the settlement monitoring data, as shown in Figure 8.

By comparing the monitored postconstruction settlement and the calculated value of the empirical equation, it can be found that the changing trend of the two is consistent. The settlement value calculated by the empirical formula is larger than the monitoring data most of the time, so the overall prediction effect is good.

3.3.2. JCO2 Monitoring Point. According to the data of JC02 monitoring point, the empirical equation is calculated by using the parameter with the water content of $18 \%$ and dry density of $1.65 \mathrm{~g} / \mathrm{cm}^{3}$, and the calculation results are compared with the settlement monitoring data, which is shown in Figure 9. The verification of JC02 monitoring point has large variations between empirical and monitoring data mainly due to the uncontrollability of field experiments. The area of loess fill foundation is large; there will be some contingency and error in the process of detection. However, it has no influence on the accuracy prediction model. Although there is a certain sudden change in the middle part of JC02 monitoring point, after the settlement of the local foundation stabilizes, its predicted value is still close to field monitoring data, so it has not influenced the accuracy on the prediction model.

By comparing the monitoring data and the empirical equation, it can be found that the changing trend of the two is consistent. The settlement value calculated by the empirical equation is slightly smaller than the monitoring data, and the overall prediction effect is good, so it can be used as a method of postconstruction settlement prediction.

3.4. Prediction of Postconstruction Settlement. According to the comparison and analysis between the above empirical equation and the monitoring data, the empirical equation is shown in equation (11) and the field monitoring data can be used better to predict the postconstruction settlement of the loess fill foundation.

Because the compaction coefficient of Yan'an City loess fill foundation is generally in the range of $0.87-0.93$, the empirical equation parameters of different compaction coefficients are different. Therefore, according to the empirical equations obtained from indoor tests, the settlement prediction and analysis of the postconstruction filled
TABLE 3: Testing parameters.

\begin{tabular}{lcccccc}
\hline $\begin{array}{l}\text { Water } \\
\text { content }\end{array}$ & $\begin{array}{c}\text { Dry } \\
\text { density }\end{array}$ & $\alpha$ & $\beta$ & $e$ & $f$ & $\begin{array}{c}r(\mathrm{kN} / \\
\left.\mathrm{m}^{3}\right)\end{array}$ \\
\hline \multirow{3}{*}{$14 \%$} & 1.60 & 0.0527 & 0.0455 & 1.5249 & -0.0174 & 18.24 \\
& 1.65 & 0.0639 & 0.03241 & 1.6203 & -0.0160 & 18.81 \\
& 1.70 & 0.0498 & 0.02934 & 1.6274 & -0.0149 & 19.38 \\
& 1.75 & 0.0494 & 0.02865 & 1.7379 & -0.0188 & 19.95 \\
\hline $18 \%$ & 1.65 & 0.0805 & 0.04795 & 1.7261 & -0.0328 & 19.47 \\
\hline
\end{tabular}

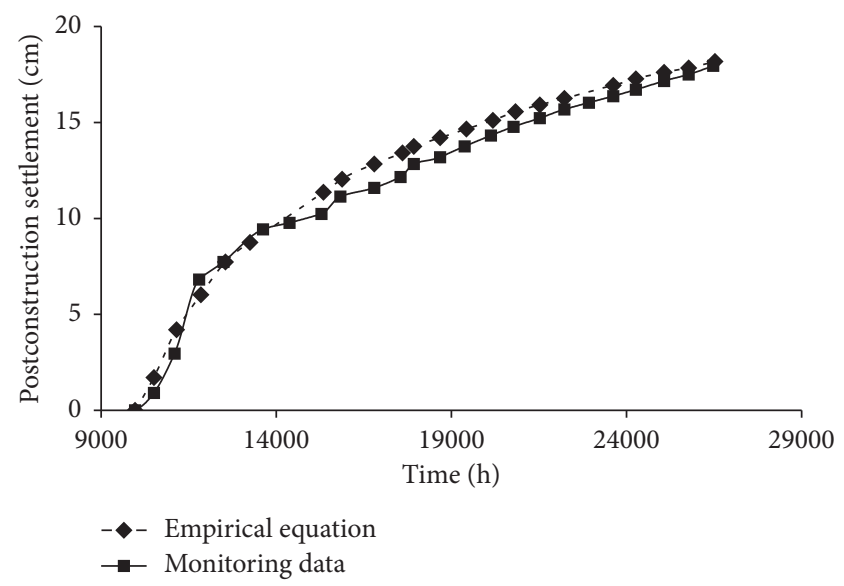

FIGURE 8: Postconstruction settlement contrast curves between the empirical equation and monitoring points JC01.

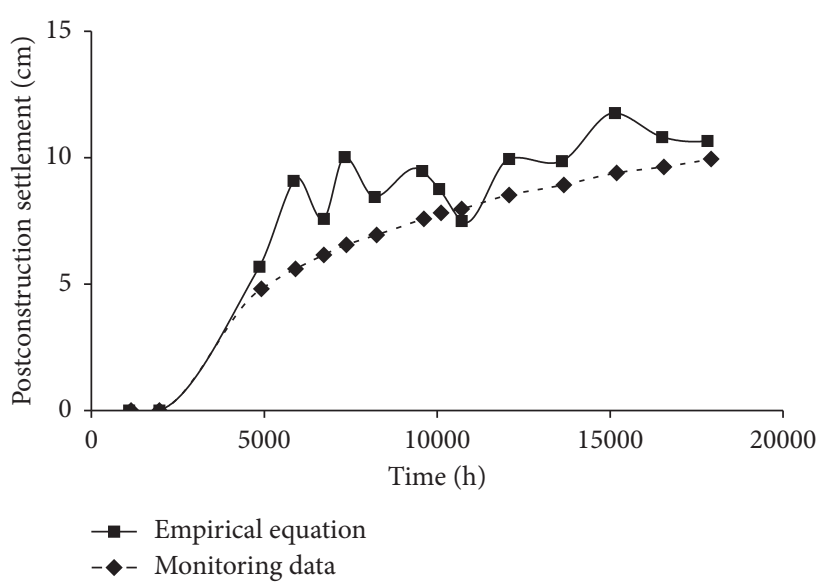

FIgURE 9: Postconstruction settlement contrast curves between the empirical equation and monitoring point JC02.

foundation are carried out. At this time, the water content is $14 \%$, and the compaction coefficient is $0.87,0.90,0.93$, and 0.95, respectively. Each compaction factor corresponds to three types of fill thickness of $10 \mathrm{~m}, 20 \mathrm{~m}$, and $30 \mathrm{~m}$, respectively.

The empirical equation with different compaction coefficients has different parameter values. When the compaction coefficient of the filling foundation is 0.87 , the parameters with water content of $14 \%$ and dry density of 
$1.62 \mathrm{~g} / \mathrm{cm}^{3}$ can be adopted. When the compaction coefficient is 0.90 , the parameters with water content of $14 \%$ and dry density of $1.67 \mathrm{~g} / \mathrm{cm}^{3}$ can be adopted. When the compaction coefficient is 0.93 , the water content is $14 \%$ and the dry density is $1.73 \mathrm{~g} / \mathrm{cm}^{3}$. When the compaction coefficient is 0.95 , the water content is $14 \%$ and the dry density is $1.75 \mathrm{~g} /$ $\mathrm{cm}^{3}$. The parameter values corresponding to different compaction coefficients are listed in Table 4.

Taking the parameters from the above table into equation (11), the settlement prediction formula and settlement prediction curve of fill foundation with different compaction coefficients can be obtained as follows.

Compaction coefficient of 0.87 :

$$
\begin{aligned}
S(t)= & 3.155 \times 10^{-3} \frac{t^{0.03897}(1.5725 t-0.0167)}{(2.5725 t-0.0167)} \\
& \cdot(18.468 H)^{(2.5725 t-0.0167) /(1.5725 t-0.0167)} .
\end{aligned}
$$

Compaction coefficient of 0.90 :

$$
\begin{aligned}
S(t)= & 2.985 \times 10^{-3} \frac{t^{0.03088}(1.6238 t-0.01545)}{(2.6238 t-0.01545)} \\
& \cdot(19.038 H)^{(2.6238 t-0.01545) /(1.6238 t-0.01545)} .
\end{aligned}
$$

Compaction coefficient of 0.93 :

$$
\begin{aligned}
S(t)= & 2.337 \times 10^{-3} \frac{t^{0.029}(1.6822 t-0.01688)}{(2.6822 t-0.01688)} \\
& \cdot(19.722 H)^{(2.6822 t-0.01688) /(1.6822 t-0.01688)} .
\end{aligned}
$$

Compaction coefficient of 0.95 :

$$
\begin{aligned}
S(t)= & 2.478 \times 10^{-3} \frac{t^{0.02865}(1.7379 t-0.01883)}{(2.7379 t-0.01883)} \\
& \cdot(19.95 H)^{(2.7379 t-0.01883) /(1.7379 t-0.01883)},
\end{aligned}
$$

where $S$ is the amount of foundation settlement $(\mathrm{cm}), t$ is the time of this process $(\mathrm{h})$, and $H$ is the thickness of loess fill foundation $(m)$.

The above formulas are used to analyze the change of postconstruction settlement with time under the deadweight of foundation with different fill thickness. The results are shown in Figures 10-12, in which the compaction coefficient of each figure is $0.87,0.90,0.93$, and 0.95 , respectively. The abscissa is the time (unit: h), the maximum pretest time is 100 years, and the ordinate is the settlement (unit: $\mathrm{cm}$ ). It can be seen from the figures that when the fill thickness is $10 \mathrm{~m}$, the settlement corresponding to the compaction coefficient from low to high is $16.8 \mathrm{~cm}, 13.6 \mathrm{~cm}$, $10.0 \mathrm{~cm}$, and $9.8 \mathrm{~cm}$; when the fill thickness is $20 \mathrm{~m}$, the settlement corresponding to the compaction coefficient from low to high is $52.4 \mathrm{~cm}, 41.8 \mathrm{~cm}, 30.1 \mathrm{~cm}$, and $29.2 \mathrm{~cm}$; when the fill thickness is $30 \mathrm{~m}$, the settlement corresponding to the compaction coefficient from low to high is $101.7 \mathrm{~cm}$, $80.6 \mathrm{~cm}, 57.5 \mathrm{~cm}$, and $55.4 \mathrm{~cm}$. When the compaction coefficient is small, the settlement of the foundation is large,
TABLE 4: Empirical equation parameters of different compaction coefficients.

\begin{tabular}{lccccc}
\hline $\begin{array}{l}\text { Compaction } \\
\text { coefficient }\end{array}$ & $\alpha$ & $\beta$ & $e$ & $f$ & $r\left(\mathrm{kN} / \mathrm{m}^{3}\right)$ \\
\hline 0.87 & 0.0583 & 0.0390 & 1.573 & -0.0167 & 18.47 \\
0.90 & 0.0568 & 0.0309 & 1.624 & -0.0155 & 19.04 \\
0.93 & 0.0496 & 0.0290 & 1.682 & -0.0169 & 19.72 \\
0.95 & 0.0494 & 0.0287 & 1.738 & -0.0188 & 19.95 \\
\hline
\end{tabular}

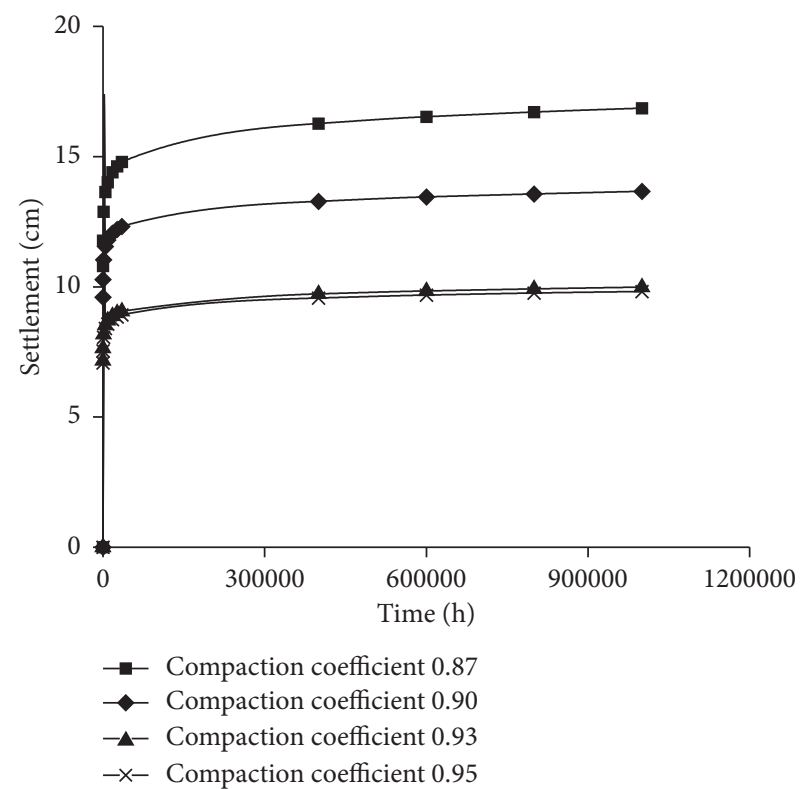

Figure 10: Settlement curves of different compaction coefficients with $10 \mathrm{~m}$ filling thickness.

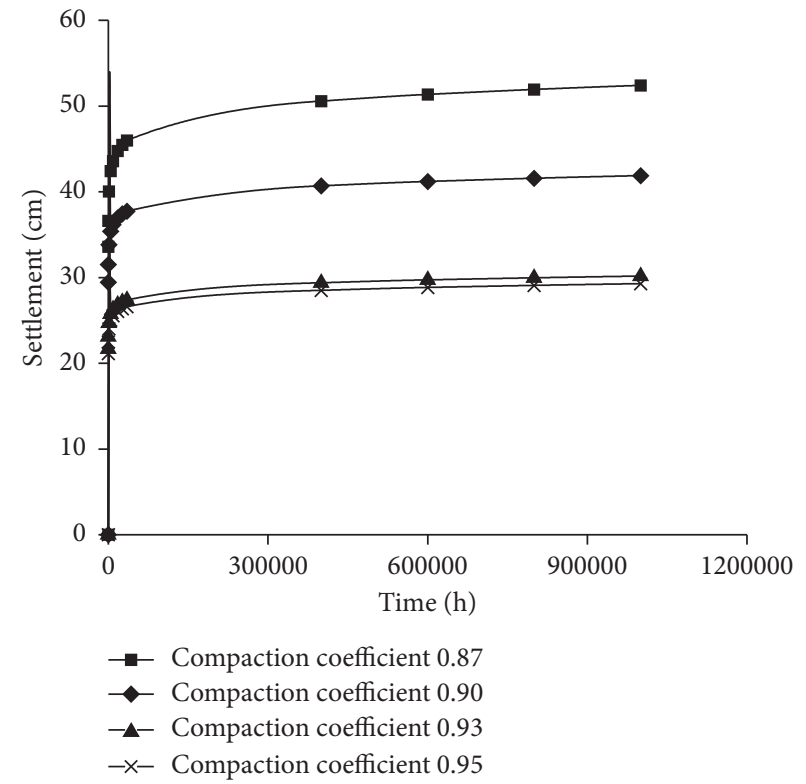

FIGURE 11: Settlement curves of different compaction coefficients with $20 \mathrm{~m}$ filling thickness. 


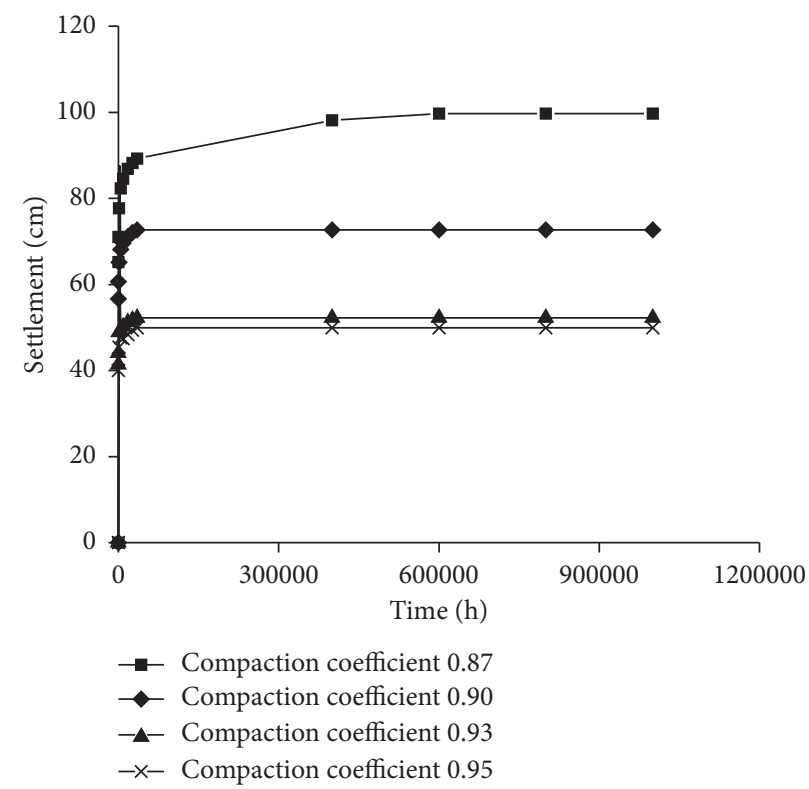

FIGURE 12: Settlement curves of different compaction coefficients with $30 \mathrm{~m}$ filling thickness.

TABLE 5: Settlement stability time of loess fill foundation with different compaction coefficients.

\begin{tabular}{|c|c|c|c|c|c|c|c|c|c|c|c|c|}
\hline Compaction coefficient & & 0.87 & & & 0.90 & & & 0.93 & & & 0.95 & \\
\hline Fill thickness & $10 \mathrm{~m}$ & $20 \mathrm{~m}$ & $30 \mathrm{~m}$ & $10 \mathrm{~m}$ & $20 \mathrm{~m}$ & $30 \mathrm{~m}$ & $10 \mathrm{~m}$ & $20 \mathrm{~m}$ & $30 \mathrm{~m}$ & $10 \mathrm{~m}$ & $20 \mathrm{~m}$ & $30 \mathrm{~m}$ \\
\hline Stable time (year) & Stable & 2.5 & 4 & Stable & 1.5 & 2.5 & Stable & 1 & 2 & Stable & 0.9 & 1.5 \\
\hline
\end{tabular}

and with the gradual increase of the compaction coefficient, the settlement of the foundation decreases rapidly. When the compaction coefficient reaches 0.93 or above, the settlement rate of the foundation tends to be gentle. In the filling process, after the compaction coefficient is greater than 0.93 , simply increasing the compaction coefficient has little effect on reducing the postconstruction settlement, and the excessive compaction coefficient has too high requirements on the construction technology and construction machinery, resulting in the increase of project cost and poor economic benefit. In consideration of economy and technology, it is suggested to control the compaction coefficient of the foundation to about 0.93 when the fill thickness is small.

How to judge whether the postconstruction settlement of filling foundation tends to be stable is a more concerning problem in engineering. In order to conduct a quantitative study on the stability time of postconstruction settlement, the settlement stability standards are considered from two aspects: total settlement and settlement rate by referring to the settlement control standards of construction industry and transportation industry and combining with the monitoring data. If the total settlement is less than or equal to $20 \mathrm{~cm}$, the foundation is considered to be basically stable [27]. If the above conditions are not met, namely, the total settlement $>20 \mathrm{~cm}$, the postconstruction settlement rate can be used to determine the foundation stability. When the postconstruction settlement rate is less than or equal to $1 \mathrm{~cm}$ per year, the fill foundation is considered to be basically stable, and the required time is the stability time [28]. Taking the settlement amount and settlement rate as the control standard, the stability time required for loess foundation with different compaction coefficients and filling height under natural water content is calculated, and the results are shown in Table 5.

\section{Conclusions}

Postconstruction settlement of loess fill foundation is an important technical index to evaluate the stability of the foundation and test the quality of filling construction. Based on the compaction test and high-pressure consolidation test, a prediction method for postconstruction settlement of loess fill foundation is proposed, and the following understandings are obtained:

(1) With the increase of water content, the lateral strain of compacted loess samples with the same density tends to increase; with the increase of pressure, the lateral strain of compacted loess samples with the same water content tends to increase. When the water content is less than $10 \%$, the dry density is greater than the compaction coefficient $1.65 \mathrm{~g} / \mathrm{cm}^{3}$, the lateral strain decreases, and the effect of dry density on the lateral strain becomes smaller.

(2) Through the high-pressure consolidation test, the stress-strain relationship and strain-time relationship of the compacted loess test are obtained by fitting, indicating that the strain-time relationship of 
the compacted loess can be expressed in the form of hyperbola, and the strain-time relationship can be expressed in the form of the power function. Combined with the layered summation method of settlement calculation, the settlement calculation formula of the loess foundation with thickness $H$ under the action of dead-weight is obtained. The formula has five unknown parameters of $\alpha, \beta, e, f$, and $r$, which can be obtained by laboratory test fitting. The effect is better through the verification of field monitoring data.

(3) Based on the above prediction equations, the settlement of loess fill foundation with compaction coefficient of $0.87,0.90,0.93$, and 0.95 and the filling thickness of $10 \mathrm{~m}, 20 \mathrm{~m}$, and $30 \mathrm{~m}$ are predicted and analyzed. The research shows that the economic and technological aspects are considered comprehensively. In the area of Yan'an City, when the thickness of the fill foundation is within $30 \mathrm{~m}$, it is suggested to control the compaction coefficient of foundation at about 0.93 .

(4) The postconstruction settlement of the loess fill foundation is directly related to the stability of the foundation. Any building can only be constructed under the premise of a stable foundation. The time required for foundation stabilization is directly related to the construction quality and benefits of the fill foundation. The greater the compaction coefficient of the fill foundation, the shorter the time required for stabilization, and the higher the project benefit. However, the excessive compaction coefficient has higher requirements on the construction machinery and construction quality of the fill foundation, which leads to an increase in the construction investment. The proposed model is to find the balance point of foundation stabilization time, compaction coefficient, and project investment in the construction of fill foundation, so as to maximize the benefits. It is of guiding significance for the implementation of future fill foundation projects.

This study is based on field engineering, and the filling loess samples are from $\mathrm{Q}_{3}$ and $\mathrm{Q}_{2}$ mixed loess samples. However, there is no consideration in the ratio of the two components, the influence of paleosol and calcium core in $\mathrm{Q}_{2}$ loess, and the influence of groundwater in the deformation of foundation. At the same time, there are fewer combinations of water content and dry density involved in the indoor test, and the universality law needs to be further studied. The stability standard of fill foundation only considers the fill thickness within $30 \mathrm{~m}$, and the applicability of fill foundation with greater thickness needs to be further verified.

\section{Data Availability}

The data used to support the findings of this study are included within the article.

\section{Conflicts of Interest}

The authors declare no conflict of interest.

\section{Authors' Contributions}

Kui Liu and Kangze Yuan designed the research. Kui Liu and Boyi Shi performed all the experiments and analyzed the data. Kangze Yuan calculated the surface area and gave suggestions. Kangze Yuan and Kui Liu wrote the paper. Kui Liu revised the manuscript. All authors read and approved the final manuscript.

\section{Acknowledgments}

This research was financially supported by the Key Research and Development Program of Shaanxi, China (Program no. 2017ZDXM-SF-087).

\section{References}

[1] H. M. Roberts, D. R. Muhs, and E. A. Bettis, "Loess records | North America," in Encyclopedia of Quaternary Science, pp. 620-628, Elsevier, Amsterdam, Netherlands, 2013.

[2] M. A. Zárate, "Loess records | South America," in Encyclopedia of Quaternary Science, pp. 629-641, Elsevier, Amsterdam, Netherlands, 2013.

[3] Z. Liu, F. Liu, F. Ma et al., "Collapsibility, composition, and microstructure of loess in China," Canadian Geotechnical Journal, vol. 53, no. 4, pp. 673-686, 2016.

[4] R. Garcia Giménez, R. Vigil de la Villa, and J. A. González Martín, "Characterization of loess in Central Spain: a microstructural study," Environmental Earth Sciences, vol. 65, no. 7, pp. 2125-2137, 2012.

[5] T. T. Kie, "Fundamental properties of loess from Northwestern China," Engineering Geology, vol. 25, no. 2-4, pp. 103-122, 1988.

[6] E. Derbyshire, R. Kemp, and X. Meng, "Variations in loess and palaeosol properties as indicators of palaeoclimatic gradients across the loess plateau of north China," Quaternary Science Reviews, vol. 14, no. 7-8, pp. 681-697, 1995.

[7] K. Wu, W. Ni, and L. Xu, "Centrifugal model testing for deformations in high-filling foundation of loess in a gully," Tehnicki Vjesnik, vol. 25, no. 2, pp. 462-469, 2018.

[8] Y. Leng, J. Peng, Q. Wang, Z. Meng, and W. Huang, "A fluidized landslide occurred in the loess plateau: a study on loess landslide in South Jingyang tableland," Engineering Geology, vol. 236, pp. 129-136, 2018.

[9] J. Peng, G. Wang, Q. Wang, and F. Zhang, "Shear wave velocity imaging of landslide debris deposited on an erodible bed and possible movement mechanism for a loess landslide in Jingyang, Xi'an, China," Landslides, vol. 14, no. 4, pp. 1503-1512, 2017.

[10] Y. Zhang, J. Tang, Z. He, J. Tan, and C. Li, "A novel displacement prediction method using gated recurrent unit model with time series analysis in the erdaohe landslide," Natural Hazards, vol. 32, 2020.

[11] Y. Zhang and L. Yang, "A novel dynamic predictive method of water inrush from coal floor based on gated recurrent unit model," Natural Hazards, vol. 53, 2020.

[12] X.-A. Li, L. Li, Y. Song, B. Hong, L. Wang, and J. Sun, "Characterization of the mechanisms underlying loess collapsibility for land-creation project in Shaanxi Province, 
China-a study from a micro perspective," Engineering Geology, vol. 249, pp. 77-88, 2019.

[13] Y. Zhang, Z. Zhang, S. Xue, R. Wang, and M. Xiao, "Stability analysis of a typical landslide mass in the three gorges reservoir under varying reservoir water levels," Environmental Earth Sciences, vol. 79, no. 1, p. 42, 2020.

[14] X. B. Tu, A. K. L. Kwong, F. C. Dai, L. G. Tham, and H. Min, "Field monitoring of rainfall infiltration in a loess slope and analysis of failure mechanism of rainfall-induced landslides," Engineering Geology, vol. 105, no. 1-2, pp. 134-150, 2009.

[15] Y. Yang and Y. W. Ju, "High fill embankment of collapsible loess settlement observation and research," Advanced Materials Research, vol. 838-841, pp. 874-877, 2013.

[16] Y. Mei, C. M. Hu, and X. Y. Wang, "Experimental research on deep collapsible loess foundation treatment by dynamic compaction under super high fill," Applied Mechanics and Materials, vol. 256-259, pp. 129-138, 2012.

[17] The National Standards Compilation Group of People's Republic of China, GB50123-1999 Standard of Soil Test Method, China Planning Press, Beijing, China, 1999.

[18] W.. JIAO, "A new parameter in the calculation of subgrade settlement-theory and application of the chord-modulus," Hydrogeology and Engineering Geology, vol. 1982, no. 1, pp. 30-33, 1982, in Chinese.

[19] C. Zhang, J. Li, and Y. He, "Application of optimized grey discrete verhulst-BP neural network model in settlement prediction of foundation pit," Environmental Earth Sciences, vol. 78, no. 15, p. 441, 2019.

[20] P. Yang, Z. Q. Cheng, and H. B. Jiang, "Calculation of settlement and inclination of gravity foundation in coral sands based on transfer matrix method," Advanced Materials Research, vol. 524-527, pp. 404-407, 2012.

[21] J. Li, S. X. Chen, and F. Yu, "The application of the creep model in the high-speed railway subgrade settlement prediction techniques," Applied Mechanics and Materials, vol. 423-426, pp. 1253-1258, 2013.

[22] Y. D. Luo, Y. C. Zhang, and L. N. Yao, "Actual example analysis of settlement prediction during soft ground treatment," Applied Mechanics and Materials, vol. 170-173, pp. 125-130, 2012.

[23] Y. Zhang, J. Tang, R. Liao et al., "Application of an enhanced BP neural network model with water cycle algorithm on landslide prediction," Stochastic Environmental Research and Risk Assessment, 2020.

[24] ASTM, ASTM standard D2487. Standard Practice for Classification of Soils for Engineering Purposes (Unified Soil Classification System), Vol. 18, American Society for Testing Materials, West Conshohocken, PA, USA, 2011.

[25] K.-S. Chen and A.-M. Sha, "Study of deformation characteristic of compacted loess," Rock and Soil Mechanics, vol. 31, no. 4, pp. 1023-1029, 2010, in Chinese.

[26] B. Liu, D. Xie, and Z. Guo, "A practical method for moistening deformation of loess foundation," Rock and Soil Mechanics, vol. 25, no. 2, pp. 270-274, 2004, in Chinese.

[27] The National Standards Compilation Group of People's Republic of China, GB50007-2011 Code for Design of Building Foundation, China Planning Press, Beijing, China, 2011.

[28] The National Standards Compilation Group of People's Republic of China, JGJ 8-2016 Code for Deformation Measurement of Building and Structure, China Planning Press, Beijing, China, 2016. 